Gynecologic and

Obstetric Investigation
Gynecol Obstet Invest 2012;74:265-273

DOI: $10.1159 / 000343759$
Received: August 23, 2011

Accepted after revision: September 3, 2012 Published online: November 10, 2012

\title{
Reduction of Miscarriages through Universal Screening and Treatment of Thyroid Autoimmune Diseases
}

\author{
Thibault Lepoutre $^{a} \quad$ Frederic Debiève $^{b} \quad$ Damien Gruson $^{a} \quad$ Chantal Daumerie $^{a}$ \\ Departments of ${ }^{a}$ Endocrinology and ${ }^{b}$ Obstetrics, Cliniques Universitaires Saint-Luc, Université Catholique de \\ Louvain, Brussels, Belgium
}

\section{Key Words}

Miscarriage - Pregnancy $\cdot$ Thyroxine treatment •

Thyroid peroxidase antibodies $\cdot$ Universal screening

\begin{abstract}
Background/Aims: Universal screening for thyroid diseases during pregnancy is controversial. Targeted screening does not identify all women with thyroid dysfunction. Furthermore, antithyroid peroxidase antibodies (TPOAb) are suspected to be associated with an increased risk of fetal loss, premature delivery and hypothyroidism. The aim of our study was to assess the rationale behind universal screening and propose thyroxine treatment in particular cases. Methods: Between January 2008 and May 2009, 537 consecutive iodine-supplemented women with a singleton pregnancy [441 TPOAb- controls and 96 TPOAb+ women (47 nontreated and 49 treated)] were evaluated using thyroid and obstetric parameters. According to our algorithm for thyroid screening in pregnancy, if thyroid-stimulating hormone (TSH) exceeded $1 \mathrm{mU} / \mathrm{l}$ in TPOAb+ women, $50 \mu \mathrm{g}$ of levothyroxine (L-T4) was prescribed. Results: The miscarriage rate was significantly higher in the nontreated TPOAb+ group compared with the treated group ( 16 vs. $0 \% ; p=0.02$ ). Compared to the control group, TSH in TPOAb+ patients was higher at the first prenatal visit prior to L-T4 treatment $(p<$ 0.01 ), while free thyroxine was higher than in the control
\end{abstract}

group after the 20th week $(p<0.05)$. Conclusions: Our study supports the potential benefit of universal screening and L-T4 treatment for autoimmune thyroid disease during pregnancy. Efforts are still needed to further decrease miscarriage rates.

Copyright $\odot 2012$ S. Karger AG, Basel

\section{Introduction}

Pregnancy represents a major challenge for the thyroid gland, contributing to thyroid dysfunction in cases where the thyroid fails or is less able to adapt adequately to pregnancy-related changes [1]. In the absence of iodine deficiency, hypothyroidism is often secondary to thyroid autoimmunity, being associated with infertility [2], obstetrical and fetal complications [3-6] and impaired neuropsychological development in children [7]. In a recent randomized trial conducted by Lazarus et al. [8], there was no preventive effect of antenatal screening and hypothyroidism treatment (at a gestational age of 12 weeks) on the intelligence quotient of 3-year-old children.

Thyroid peroxidase antibodies (TPOAb) are detected in $10 \%$ of pregnant women. Several studies have showed

This paper was presented as a poster at the 14th International Thyroid Congress, Paris, France, in September 2010.

\section{KARGER}

Fax +4161306 1234

E-Mail karger@karger.ch

www.karger.com (c) 2012 S. Karger AG, Basel

0378-7346/12/0744-0265\$38.00/0

Accessible online at:

www.karger.com/goi
Chantal Daumerie

Endocrinology Department, Cliniques Universitaires Saint-Luc

Université Catholique de Louvain, Avenue Hippocrate, 10

BE-1200 Brussels (Belgium)

E-Mail chantal.daumerie@uclouvain.be 
a positive association between TPOAb and miscarriage $[9,10]$, maternal hypothyroidism [11], preterm delivery $[12,13]$, postpartum thyroiditis [14], maternal morbidity in later life [15] and impaired neuropsychological development in children [16-18]. In 2006, Negro et al. [19] demonstrated a significant decrease in miscarriage $(-75 \%)$ and premature delivery $(-69 \%)$ rates in TPOAb+ women treated with levothyroxine (L-T4) compared with the nontreated group. Due to the lack of intervention studies, the Endocrine Society's Clinical Practice Guidelines of 2007 [20] and, more recently, the American Thyroid Association [21] recommended targeted high-risk case finding to identify women with thyroid dysfunction. However, Vaidya et al. [22] revealed the limitations of targeted screening, which overlooked one third of pregnant women with hypothyroidism. Likewise, Horacek et al. [23] recently reported the benefit of universal screening, which detected twice as many thyroid disorders as targeted high-risk case finding. In 2010, in a study comparing the ability of universal and targeted screening to detect thyroid hormonal dysfunction, Negro et al. [24] showed no significant differences between these two screening strategies. Nonetheless, the question arises as to whether it is acceptable to leave maternal thyroid disease undiagnosed. In 2009, a study conducted by Debiève et al. [25] proposed treating TPOAb+ women with L-T4 substitution if the thyroid-stimulating hormone (TSH) levels were higher than $1 \mathrm{mU} / \mathrm{l}$.

In this study, we assess whether universal thyroid screening should be undertaken in all pregnant women, with L-T4 treatment being implemented in particular cases, and if early L-T4 treatment could decrease the miscarriage rate in $\mathrm{TPOAb}+$ women.

\section{Subjects and Methods}

Patients and Design

Thyroid screening of pregnant women based on TSH and TPOAb values was introduced at our institution in 2004. A dose of $50 \mu \mathrm{g}$ of L-T4 is prescribed if TSH levels are higher than $1 \mathrm{mU} / \mathrm{l}$ and the TPOAb titer is positive [25] ( $>9 \mathrm{U} / \mathrm{ml})$ at the first prenatal visit. This TSH value of $1 \mathrm{mU} / \mathrm{l}$ was arbitrarily chosen based initially on results of Glinoer et al. [26] and then on our own. This study showed that mean TSH levels during the first and, to a lesser extent, second trimester never exceeded $1 \mathrm{mU} / \mathrm{l}$. These data were confirmed by our own clinical experience [25]. TSH values were monitored and L-T4 replacement therapy adjusted in order to achieve TSH levels between 1 and $2 \mathrm{mU} / \mathrm{l}$.

Our descriptive study retrospectively reviewed the files of 823 consecutive iodine-supplemented women with a singleton pregnancy who attended the prenatal clinic at the Cliniques Universitaires Saint-Luc, Brussels, Belgium, between January 2008 and
May 2009. The study was approved by the ethical committee. Thyroid function parameters, namely TSH, free thyroxine (fT4) and TPOAb, were assessed at the first prenatal visit during the first trimester. The exclusion criteria were TSH values above the reference range $(>3.5 \mathrm{mU} / \mathrm{l})$ at the first prenatal visit, L-T4 treatment starting before the onset of pregnancy, Basedow disease, thyroidectomy, other serious diseases that could influence thyroid hormone levels (i.e. diabetes mellitus, HIV immunization and cirrhosis) and therapeutic abortion. Figure 1 shows the distribution of screened patients. Overall, $96 \mathrm{TPOAb}+$ women were included in the analysis; 49 were treated at the first prenatal visit (group 1) and 47 were not treated (group 2). Furthermore, 441 TPOAb- women (group 3) served as a control group. All patients included were followed until delivery and received vitamin supplements containing $150 \mu \mathrm{g}$ of potassium iodide/day.

\section{Laboratory Methods}

TSH, fT4 and TPOAb titers were measured using automated immunoassays with chemiluminescence detection (DxI 800 Access, Beckman Coulter, USA). The hospital laboratory reference values were $0.2-3.5 \mathrm{mU} / \mathrm{l}$ for TSH, $0.6-1.4 \mathrm{ng} / \mathrm{dl}$ for fT4 and $<9$ $\mathrm{U} / \mathrm{ml}$ for TPOAb. Coefficients of variation were 10.62, 4.96, 4.55 and $3.72 \%$ for the TSH assay at concentrations of $0.027,1,8.18$ and $28.59 \mathrm{mU} / \mathrm{l}$, respectively, and $7.42,3.28$ and $4.56 \%$ for the fT4 assay at concentrations of $0.47,1.21$ and $4.3 \mathrm{ng} / \mathrm{dl}$, respectively. For the TPOAb assay, the coefficient of variation was $<12 \%$ at a concentration of $\geq 0.6 \mathrm{IU} / \mathrm{ml}$.

\section{Obstetric Complications}

Obstetric complications were classified into three groups. The first group involved miscarriages during the first trimester $(\leq 13$ weeks). The second group of complications included delivery complications, notably preterm delivery ( $<37$ weeks of gestation), neonatal hypotrophy, cesarean section, placental abruption and delivery hemorrhage. The third group comprised various medical conditions, namely pregnancy-induced hypertension, preeclampsia and gestational diabetes. Gestational hypertension was defined as blood pressure $>140 / 90 \mathrm{~mm} \mathrm{Hg}$. Preeclampsia was diagnosed according to the criteria of the American College of Obstetricians and Gynecologists and the National High Blood Pressure Education Program. Gestational diabetes was defined as two or more abnormal values on the oral glucose tolerance test. The distribution of TSH, fT4 and TPOAb levels was studied at different time points during pregnancy, namely at $\leq 10,12,15,20,30$ and 35 weeks.

\section{Statistics}

Statistical analysis was performed using the MedCalc 7.2.1.0 package (Medcalc Software, Mariakerke, Belgium). For obstetric complications, categorical variables were compared using Fisher's exact test owing to the low number of observations. $\chi^{2}$ or Fisher's exact test were used to compare patient characteristics. For continuous variables, an analysis of variance test was used. When the distribution was found to be abnormal, data were logarithmically transformed. Logistic regression analysis was used to assess the relationship between certain patient characteristics (i.e. age, TSH, $\mathrm{TPOAb}$ titer, maternal weight and weight gain) and the occurrence of miscarriage. A $p$ value of $<0.05$ was considered significant. 


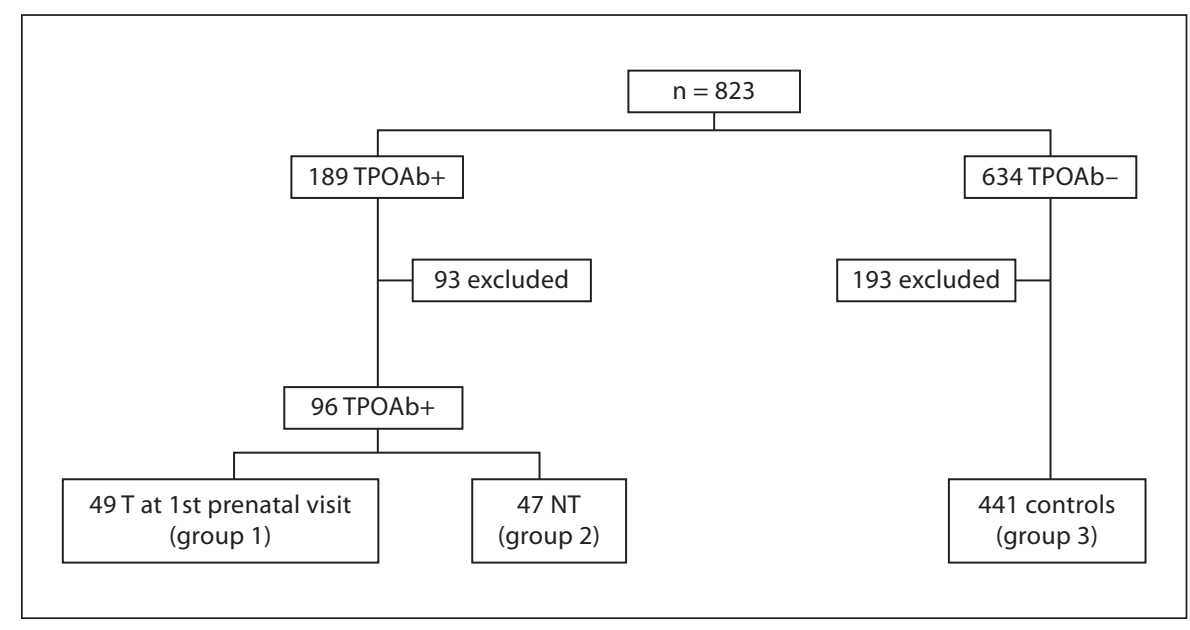

Fig. 1. Flow chart of patients screened for thyroid tests. Patients were excluded from the control group for the following reasons: 55 for thyroid dysfunction history or previous L-T4 treatment; 62 missing during pregnancy and 16 with incomplete data; 10 for medical abortions; 5 for hypothyroidism $(>3.5 \mathrm{mU} / \mathrm{l})$ at the first prenatal visit; 5 for serious diseases (diabetes mellitus, HIV immunization or cirrhosis); 12 for multiple pregnancies, and 28 were working members. Patients were excluded from the TPOAb+

\section{Results}

The clinical characteristics of the patients at the first prenatal visit are shown in table 1 . No significant differences were observed between the groups $(p>0.05)$. Screening and treatment rates during the first trimester were $69 \%$ in group 1 [34/49; $82 \%(28 / 34)$ at $\leq 10$ weeks], $66 \%(31 / 47)$ in group $2(\mathrm{p}=0.83$ compared with group 1 , Fisher's exact test) and 71\% (311/441) in the control group. Patients who were not screened during first trimester, and thus did not receive treatment for group 1, were not considered in the analysis of the miscarriage rate. The numbers of studied patients were 34,31 and 311 for groups 1,2 and 3, respectively (fig. 1). The initial L-T4 dose in group 1, started as soon as TPOAb was detected and TSH was $>1 \mathrm{mU} / \mathrm{l}$, remained unchanged throughout the pregnancy in $88 \%$ of patients $(43 / 49)$. In order to reach and maintain a TSH level between 1 and $2 \mathrm{mU} / \mathrm{l}$, the L-T4 dose was increased in 4 patients, while the dose was decreased in 2 due to $\mathrm{TSH}<1 \mathrm{mU} / \mathrm{l}$.

\section{Obstetric Complications}

Among group 1 patients with TPOAb+ who were treated at the first prenatal visit there were no cases of miscarriage (table 2a). A significant difference of $16 \%$ was observed in the miscarriage rates between this group for the following reasons: 33 for L-T4 treatment started before the onset of pregnancy; 7 for Basedow disease; 20 for hypothyroidism at the first prenatal visit; 19 missing during pregnancy and 1 with incomplete data; 1 for HIV immunization; 4 for multiple pregnancies, and 8 were working members. First trimester screening (and treatment) rate: $34 / 49(69 \%)$ for group 1, 31/47 (66\%) for group 2 and 311/441 (71\%) for group 3. T = Treated; $\mathrm{NT}=$ nontreated.

Table 1. Clinical characteristics of pregnant women in the different groups

\begin{tabular}{lclll}
\hline $\begin{array}{l}\text { Clinical } \\
\text { characteristics }\end{array}$ & $\begin{array}{l}\text { Group 1 } \\
(\mathrm{n}=49)\end{array}$ & $\begin{array}{l}\text { Group 2 } \\
(\mathrm{n}=47)\end{array}$ & $\begin{array}{l}\text { Group 3 } \\
(\mathrm{n}=441)\end{array}$ & $\begin{array}{l}\mathrm{p} \\
\text { value }\end{array}$ \\
\hline Maternal age, years & $31.5 \pm 5.5$ & $32.5 \pm 5.3$ & $31.9 \pm 5.1$ & 0.6 \\
Maternal weight, kg & $63 \pm 10.4$ & $61.3 \pm 12.5$ & $62.9 \pm 11.7$ & 0.5 \\
Weight gain, kg & $13.3 \pm 6$ & $12.8 \pm 4.7$ & $14 \pm 5.6$ & 0.7 \\
Primigravidity, \% & 32.7 & 25.5 & 28.8 & 0.7 \\
Obstetrical history, \% & 28.6 & 42.6 & 34 & 0.3 \\
Infertility, \% & 16.3 & 8.5 & 8.6 & $>0.1$ \\
\hline
\end{tabular}

Values are given as means \pm SD or percentages. Primigravidity was defined as first-time pregnancy. Obstetrical history was considered positive if the difference between the gravidity and parity was higher than 1. $\chi^{2}$ test was used for comparison of primigravidity and obstetrical history and Fisher's exact test between groups for comparison of infertility. An analysis of variance test was used for continuous variables (maternal age, weight and weight gain).

group and the nontreated group (group 2; 5/31; $\mathrm{p}=0.02$ ). Four of these 5 nontreated TPOAb+ women with early miscarriage had TSH values above $1 \mathrm{mU} / \mathrm{l}$. The control group (group 3) had a miscarriage rate of $8 \%$ (25/311), which was similar to that of the nontreated TPOAb+ patients (group 2). No other significant differences re- 
Table 2. Obstetric complications in the treated TPOAb+ group (group 1) versus the nontreated TPOAb+ group (group 2) and in the nontreated TPOAb+ group (group 2) versus controls (group 3)

a Miscarriage

\begin{tabular}{|c|c|c|c|c|c|}
\hline & \multicolumn{2}{|l|}{$\mathrm{TPOAb}+$} & \multirow{2}{*}{$\frac{\text { TPOAb- }}{\text { group } 3(n=311)}$} & \multicolumn{2}{|l|}{$\mathrm{p}$ value } \\
\hline & group $1(n=34)$ & group $2(n=31)$ & & group 1 vs. 2 & group 3 vs. 2 \\
\hline Miscarriage, $\mathrm{n}$ & $0(0)$ & $5(16.1)$ & $25(8)$ & 0.02 & 0.17 \\
\hline
\end{tabular}

b Delivery complications and gestational hypertension/diabetes

\begin{tabular}{|c|c|c|c|c|c|}
\hline & group $1(n=49)$ & group $2(n=47)$ & $\frac{\text { TPOAb- }}{\text { group } 3(n=441)}$ & group 1 vs. 2 & group 3 vs. 2 \\
\hline \multicolumn{6}{|l|}{ Delivery complications, $\mathrm{n}$} \\
\hline Preterm delivery & $3(6.1)$ & $4(10)$ & $29(7.2)$ & 0.69 & 0.52 \\
\hline Neonatal hypotrophy & $2(4.1)$ & $0(0)$ & $5(1.2)$ & 0.5 & 1 \\
\hline Cesarean section & $8(16.3)$ & $8(20)$ & $94(23.3)$ & 0.78 & 0.84 \\
\hline Delivery hemorrhage & $14(26.5)$ & $14(22.5)$ & $137(28.8)$ & 0.81 & 0.47 \\
\hline \multicolumn{6}{|c|}{ Gestational hypertension/diabetes, $\mathrm{n}$} \\
\hline Hypertension & $1(2)$ & $2(5)$ & $13(3.2)$ & 0.59 & 0.64 \\
\hline Preeclampsia & $1(2)$ & $2(5)$ & $8(2)$ & 0.59 & 0.23 \\
\hline Gestational diabetes & $2(4.1)$ & $1(2.5)$ & $7(1.7)$ & 1 & 0.53 \\
\hline
\end{tabular}

Numbers in parentheses represent percentages, and totals are a percentage of the different patients with (at least) one obstetric complication.

lating to delivery and medical conditions, such as gestational hypertension or diabetes, were observed (table $2 b)$.

\section{Evolution of Thyroid Function Tests}

Figure 2 illustrates the TSH and fT4 levels at different time points throughout pregnancy for groups 1 (treated at the first prenatal visit), 2 (nontreated) and 3 (control). At baseline prior to L-T4 treatment, mean TSH values were significantly higher in the treated group compared with the control group $(1.61 \pm 0.77$ vs. $1.05 \pm 0.7 \mathrm{mU} / \mathrm{l}$; $\mathrm{p}=0.005)$. After initiating L-T4 therapy, TSH values decreased and then remained stable. No other difference was subsequently found. Despite higher values in the nontreated group, fT4 distribution did not reveal any significant differences at baseline. Appropriate L-T4 substitution resulted in stable fT4 values in the treated group during pregnancy. In contrast, in the two other groups (nontreated and control), fT4 decreased in relation to baseline values. From week 20 onwards, fT4 values in the control group differed significantly from those in the treated group $(0.75 \pm 0.09$ vs. $0.68 \pm 0.12 \mathrm{ng} / \mathrm{dl}, 0.72 \pm$ 0.1 vs. $0.62 \pm 0.08 \mathrm{ng} / \mathrm{dl}$, and $0.74 \pm 0.1$ vs. $0.63 \pm 0.09$ $\mathrm{ng} / \mathrm{dl}$ at 20, 30 and 35 weeks, respectively; $\mathrm{p}<0.05$ ). TPOAb titers were 2-3 times higher in the treated group compared with the nontreated group throughout pregnancy. Lastly, antibody levels decreased by $65-70 \%$ between the first trimester and 9th month of pregnancy.

\section{Discussion}

Our study evaluated the rationale behind universal thyroid function screening in women and the potential benefits of thyroxine treatment in particular cases during early pregnancy. The analysis of obstetric complications revealed a significant difference in miscarriage rates in $\mathrm{TPOAb}+$ women treated at the first prenatal visit (group 
Fig. 2. Distribution of TSH (a) and fT4 levels (b) at different time points during pregnancy. Continuous lines represent the mean, and the box plots represent the first quartile, median and third quartile. ${ }^{\mathrm{a}} \mathrm{p}<$ 0.05 : group 1 vs. group $3 ;^{b} \mathrm{p}<0.05$ : group 1 vs. groups 2 and 3.

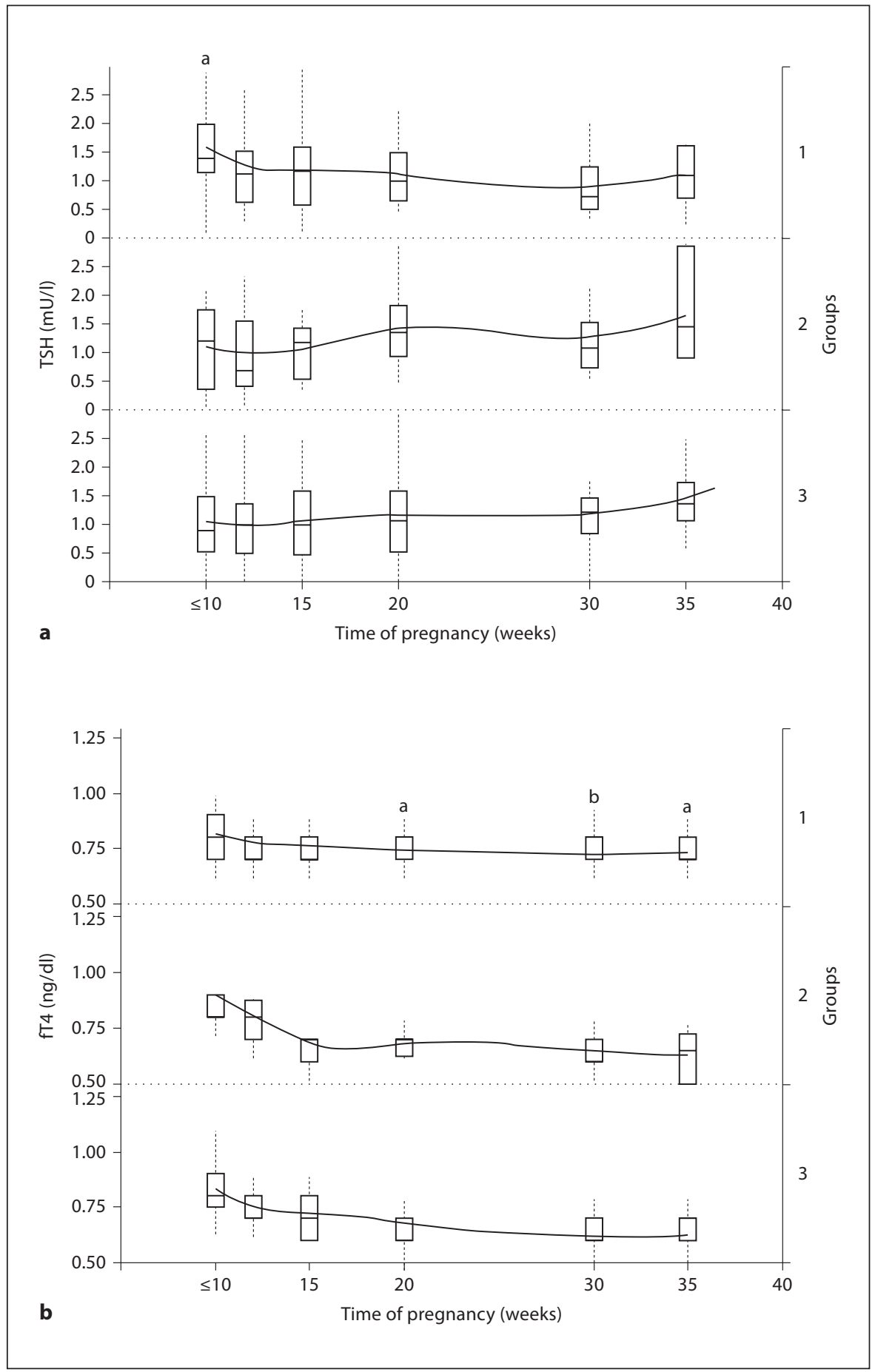

1) as compared with the nontreated group (group 2), with no miscarriages being observed in the treated TPOAb+ women. In contrast, $4 \mathrm{TPOAb}+$ women with a TSH value $>1 \mathrm{mU} / \mathrm{l}$ had an early miscarriage before initiating L-T4 therapy.
The impact of TPOAb levels on miscarriage rates is controversial. The studies of Iijima et al. [27] and Stagnaro-Green et al. [9] did not find any correlation between these two parameters. In contrast, another study reported higher TPOAb titers in women with miscarriage com- 
Table 3. Differences in age and TSH levels in TPOAb+ women compared to TPOAb- women, in studies on the association between thyroid autoimmunity and miscarriage

\begin{tabular}{|c|c|c|c|c|}
\hline & TPOAb+ women & TPOAb- women & Difference & $\mathrm{p}$ \\
\hline \multicolumn{5}{|l|}{ Age, years } \\
\hline Bussen and Steck [41] & $31 \pm 5.2$ & $30.3 \pm 4.5$ & +0.7 & NS \\
\hline Glinoer et al. [43] & $29.3 \pm 1$ & $27.3 \pm 2$ & +2 & $<0.001$ \\
\hline Lejeune et al. [44] & $28.2 \pm 9.5$ & $27.2 \pm 6.8$ & +1 & 0.06 \\
\hline Pratt et al. [45] & $33 \pm 2.9$ & $34 \pm 3.4$ & -1 & NS \\
\hline Rushworth et al. [47] & $34(20-41)$ & $34(22-46)$ & 0 & NS \\
\hline Poppe et al. [48] & $33.2 \pm 4.6$ & $31.6 \pm 5.4$ & +1.6 & NS \\
\hline Poppe et al. [49] & $33 \pm 2.9$ & $34 \pm 3.4$ & -1 & NS \\
\hline Kim et al. [50] & $34.3 \pm 6.4$ & $31.2 \pm 6.7$ & +3.1 & NS \\
\hline Present study & $31.5 \pm 5.5$ & $31.9 \pm 5.1$ & -0.4 & NS \\
\hline Bagis et al. [42] & $1.86 \pm 1.8$ & $1.17 \pm 0.9$ & 0.69 & $<0.001$ \\
\hline Poppe et al. [48] & $1.6(0.02-4.1)$ & $1.3(0.05-3.6)$ & 0.3 & NS \\
\hline Mecacci et al. [51] & 3.62 & 1.29 & 2.33 & 0.009 \\
\hline Present study & $1.61 \pm 0.77$ & $1.05 \pm 0.7$ & 0.56 & 0.005 \\
\hline
\end{tabular}

Values are shown as means \pm SD or medians (range). NS $=$ Not significant.

pared to those without [28]. Recent meta-analyses have emphasized the association between the presence of autoimmune thyroid antibodies and pregnancy outcomes $[10,29]$. Mild thyroid failure or decreased capacity to modify thyroid hormones appeared to play a predominant role. As summarized in table 3 , in our population the mean TSH levels were significantly higher in women with TPOAb+ before LT- 4 treatment (group 1; $1.61 \pm$ 0.77 vs. $1.05 \pm 0.7 \mathrm{mU} / \mathrm{l}$ in the TPOAb- group; $\mathrm{p}=0.005$ ). Another important finding to consider is age, as we know that greater maternal age is a risk factor for miscarriage. Most of the studies reported a slightly greater age in TPOAb+ women (table 3). However, despite a trend toward higher age and TSH levels in patients with miscarriage, parameters such as age, TSH, TPOAb titer and maternal weight were not significantly associated with this observation, probably because of the low number of patients who miscarriage in the TPOAb+ group.

Our results, along with those of Negro et al. [19], confirmed the beneficial effects of L-T4 substitution, as reflected by the decreased miscarriage and premature delivery rates in TPOAb+ women treated with low-dose L-T4 [30]. In our study, nontreated TPOAb+ women ex- hibited TSH values similar to those of the control group. Based on our algorithm, women with TSH values $<1$ $\mathrm{mU} / \mathrm{l}$ were not offered any treatment. In our population, fT4 levels were lower than in previous studies [31], which may be accounted for by the slight iodine deficiency in the Belgian population [32].

Another important parameter to consider is the normal TSH cutoff value in pregnant TPOAb- women. Negro et al. [33] found an increased pregnancy loss during the first trimester in women with TSH values between 2.5 and $5 \mathrm{mU} / \mathrm{l}$ compared to women with TSH $\leq 2.5 \mathrm{mU} / \mathrm{l}$. These results support revising the established cutoff of 'normal' TSH in pregnant women up to $2.5 \mathrm{mU} / \mathrm{l}$.

Although universal thyroid screening is not totally accepted, several studies in favor of universal screening demonstrated the potential consequences of thyroid dysfunction on maternal and fetal health as well as the beneficial effects of thyroxine treatment [2-19, 22, 23]. Despite finding no significant decrease in obstetric complications with universal screening and case finding, the results of Negro et al. [24] showed fewer obstetric complications in the low-risk group identified by universal screening and benefiting from hypo-/hyperthyroidism 
treatment, thus providing strong evidence that universal screening for TPOAb and TSH in pregnant women should be considered [34]. Moreover, the first study evaluating the cost-effectiveness of screening all pregnant women for autoimmune thyroid disease during the first trimester demonstrated a cost-saving result compared with no screening [35].

Despite a lack of consensus among professional organization guidelines regarding thyroid dysfunction screening, a survey conducted in Maine, USA, showed that many practitioners have already implemented routine TSH testing in pregnant women [36]. Recently, a European survey found similar results, with $42 \%$ of responders screening all pregnant women for thyroid dysfunction [37]. Klubo-Gwiezdzinska et al. [38] clearly demonstrated the necessity of updating and promulgating new guidelines for L-T4 treatment during pregnancy.

The distinctiveness of this present study is its use of an algorithm, which has been employed at our institution since 2004, allowing us to highlight the benefits and difficulties of universal screening and treatment of autoimmune thyroid diseases. In spite of our algorithm, the differences observed in the incidence of miscarriages in the two TPOAb+ groups reflect the difficulties inherent in early pregnancy screening. For this reason, we suggest conducting screening prior to pregnancy rather than at 6-7 weeks in order to reduce the incidence of miscarriage in $\mathrm{TPOAb}+$ women. Improved cooperation and communication between endocrinologists and obstetricians in addition to an increased awareness about the risks of thyroid dysfunction among the general population should be emphasized [39].

One of the strengths of our study is its concern for the real-life treatment of patients, which helped to highlight some of the erroneous parts of our algorithm. In addition, a wide range of parameters for obstetric complications were evaluated. To our knowledge, this is the first study evaluating the different aspects of universal screening and autoimmune thyroid disease treatment in daily clinical practice. One limitation of this retrospective study with a descriptive design was the lack of comparisons with another form of screening (e.g. case finding). Other limitations include the cross-sectional analysis of TSH and fT4 distribution, use of nonspecific reference values for pregnancy in the algorithm and the absence of certain variables, such as socioeconomic status, body mass index and patient ethnicity, as significant differences relating to ethnicity are found for specific reference intervals for thyroid function tests [40].

Reduction of Miscarriages through Universal Thyroid Screening
A longitudinal study involving normal TPOAb and iodine-supplemented women should be performed in order to establish the gestational age-specific reference intervals for TSH and fT4 and better adapt possible L-T4 treatments for $\mathrm{TPOAb}+$ pregnant women.

\section{Conclusions}

Our study supports the potential benefit of early universal thyroid screening, as L-T4 treatment for TPOAb+ pregnant women who were diagnosed via universal screening appeared to reduce miscarriage rates. Furthermore, L-T4 therapy was offered to women with TPOAb+ and TSH values $>1 \mathrm{mU} / \mathrm{l}$. To further decrease miscarriage rates, efforts are still required to conduct universal thyroid screening prior to pregnancy or as soon as pregnancy is confirmed. Optimal cooperation and communication between endocrinologists and obstetricians is also necessary. Ideally, randomized placebo-controlled studies are needed in order to confirm the potential benefits of universal screening and treatment of autoimmune thyroid disease during pregnancy.

\section{Acknowledgments}

We would like to thank Prof. Pierre Bernard and Corinne Hubinont from the Obstetrics Department and Prof. Marie-Françoise Vincent from the Medical Biochemistry Department for their collaboration and providing the medical records. We also acknowledge the assistance of Prof. Annie Robert and Jean Cumps with the statistical analysis.

References

1 Glinoer D: The regulation of thyroid function in pregnancy: pathways of endocrine adaptation from physiology to pathology. Endocr Rev 1997;18:404-433.

2 Poppe K, Velkeniers B, Glinoer D: The role of thyroid autoimmunity in fertility and pregnancy. Nat Clin Pract Endocrinol Metab 2008;4:394-405.

3 Abalovich M, Gutierrez S, Alcaraz G, Maccallini G, Garcia A, Levalle O: Overt and subclinical hypothyroidism complicating pregnancy. Thyroid 2002;12:63-68.

$\checkmark 4$ Casey BM, Dashe JS, Wells CE, McIntire DD, Byrd W, Leveno KJ, Cunningham FG: Subclinical hypothyroidism and pregnancy outcomes. Obstet Gynecol 2005;105:239-245. 
5 Allan WC, Haddow JE, Palomaki GE, Williams JR, Mitchell ML, Hermos RJ, Faix JD, Klein RZ: Maternal thyroid deficiency and pregnancy complications: implications for population screening. J Med Screen 2000;7: 127-130.

6 6 Leung AS, Millar LK, Koonings PP, Montoro $\mathrm{M}$, Mestman JH: Perinatal outcome in hypothyroid pregnancies. Obstet Gynecol 1993; 81:349-353.

7 Haddow JE, Palomaki GE, Allan WC, Williams JR, Knight GJ, Gagnon J, O’Heir CE, Mitchell ML, Hermos RJ, Waisbren SE, Faix JD, Klein RZ: Maternal thyroid deficiency during pregnancy and subsequent neuropsychological development of the child. N Eng J Med 1999;341:549-555.

8 Lazarus JH, Bestwick JP, Channon S, Paradice R, Maina A, Rees R, Chiusano E, John $\mathrm{R}$, Guaraldo V: Antenatal thyroid screening and childhood cognitive function. N Engl J Med 2012;366:493-501.

-9 Stagnaro-Green A, Roman SH, Cobin RH, el-Harazy E, Alvarez-Marfany M, Davies TF: Detection of at risk pregnancy using highly sensitive assays for thyroid autoantibodies. JAMA 1990;264:1422-1425.

10 Prummel MF, Wiersinga WM: Thyroid autoimmunity and miscarriage. Eur J Endocrinol 2004;150:751-755.

-11 Glinoer D, Riahi M, Grün JP, Kinthaert J: Risk of subclinical hypothyroidism in pregnant women with asymptomatic autoimmune thyroid disorders. J Clin Endocrinol Metab 1994;79:197-204.

-12 Stagnaro-Green A: Maternal thyroid disease and preterm delivery. J Clin Endocrinol Metab 2009;94:21-25.

-13 Negro R, Schwartz A, Gismondi R, Tinelli A, Mangieri T, Stagnaro-Green A: Thyroid antibody positivity in the first trimester of pregnancy is associated with negative pregnancy outcomes. J Clin Endocrinol Metab 2011;96:E920-E924.

14 Premawardhana LD, Parkes AB, John R, Harris B, Lazarus JH: Thyroid peroxidase antibodies in early pregnancy: utility for prediction of postpartum thyroid dysfunction and implications for screening. Thyroid 2004;14:610-615.

15 Männistö T, Vääräsmäki M, Pouta A, Hartikainen AL, Ruokonen A, Surcel HM, Bloigu A, Järvelin MR, Suvanto E: Thyroid dysfunction and autoantibodies during pregnancy as predictive factors of pregnancy complications and maternal morbidity in later life. J Clin Endocrinol Metab 2010;95:1084-1094.

- 16 Pop VJ, de Vries E, van Baar AL, Waelkens JJ, de Rooy HA, Horsten M, Donkers MM, Komproe IH, van Son MM, Vader HL: Maternal thyroid peroxidase antibodies during pregnancy: a marker of impaired child development? J Clin Endocrinol Metab 1995;80: 3561-3566.
17 Pop VJ, Kuijpens JL, van Baar AL, Verkerk G, van Son MM, de Vijlder JJ, Vulsma T, Wiersinga WM, Drexhage HA, Vader HL: Low maternal free thyroxine concentrations during early pregnancy are associated with impaired psychomotor development in infancy. Clin Endocrinol (Oxf) 1999;50:149-155.

18 Li Y, Shan Z, Teng W, Yu X, Li Y, Fan C, Teng X, Guo R, Wang H, Li J, Chen Y, Wang W, Chawinga M, Zhang L, Yang L, Zhao Y, Hua $\mathrm{T}$ : Abnormalities of maternal thyroid function during pregnancy affect neuropsychological development of their children at 2530 months. Clin Endocrinol (Oxf) 2010;72: 825-829.

19 Negro R, Formoso G, Mangieri T, Pezzarossa A, Dazzi D, Hassan H: Levothyroxine treatment in euthyroid pregnant women with autoimmune thyroid disease: effects on obstetrical complications. J Clin Endocrinol Metab 2006;91:2587-2591.

20 Abalovich M, Amino N, Barbour LA, Cobin RH, De Groot LJ, Glinoer D, Mandel SJ, Stagnaro-Green A: Management of thyroid dysfunction during pregnancy and postpartum: an Endocrine Society Clinical Practice Guideline. J Clin Endocrinol Metab 2007; 92:S1-S47.

21 Stagnaro-Green A, Abalovich M, Alexander E, Azizi F, Mestman J, Negro R, Nixon A, Pearce EN, Soldin OP, Sullivan S, Wiersinga W: Guidelines of the American Thyroid Association for the diagnosis and management of thyroid disease during pregnancy and postpartum. Thyroid 2011;21:1081-1125.

22 Vaidya B, Anthony S, Bilous M, Shields B, Drury J, Hutchison S, Bilous R: Detection of thyroid dysfunction in early pregnancy: universal screening or targeted high-risk case finding? J Clin Endocrinol Metab 2007;92: 203-207.

23 Horacek J, Spitalnikova S, Dlabalova B, Malirova E, Vizda J, Svilias I, Cepkova J, Mc Grath C, Maly J: Universal screening detects two-times more thyroid disorders in early pregnancy than targeted high-risk case finding. Eur J Endocrinol 2010;163:645-650.

24 Negro R, Schwartz A, Gismondi R, Tinelli A, Mangieri T, Stagnaro-Green A: Universal screening versus case finding for detection and treatment of thyroid hormonal dysfunction during pregnancy. J Clin Endocrinol Metab 2010:95:1699-1707.

25 Debiève F, Dulière S, Bernard P, Hubinont C, De Nayer P, Daumerie C: To treat or not to treat euthyroid autoimmune disorder during pregnancy. Gynecol Obstet Invest 2009;67: 178-182.

26 Glinoer D, de Nayer P, Bourdoux P, Lemone M, Robyn C, van Steirteghem A, Kinthaert J, Lejeune B: Regulation of maternal thyroid during pregnancy. J Clin Endocrinol Metab 1990;71:276-287.

27 Iijima T, Tada H, Hidaka Y, Mitsuda N, Murata Y, Amino N: Effects of autoantibodies on the course of pregnancy and fetal growth. Obstet Gynecol 1997;90:364-369.
28 Wilson R, Ling H, MacLean MA, Mooney J, Kinnane D, McKillop JH, Walker JJ: Thyroid antibody titer and avidity in patients with recurrent miscarriage. Fertil Steril 1999;71: 568-561.

29 Thangaratinam S, Tan A, Know E, Kilby MD, Franklyn J, Coomarasamy A: Association between thyroid autoantibodies and miscarriage and preterm birth: meta-analysis of evidence. BMJ 2011;342:d2616.

30 Glinoer D: Miscarriage in women with positive anti-TPO antibodies: is thyroxine the answer? J Clin Endocrinol Metab 2006;91: 2500-2502.

31 Stricker R, Echenard M, Eberhart R, Chevailler MC, Perez V, Quinn FA, Stricker R: Evaluation of maternal thyroid function during pregnancy: the importance of using gestational age-specific reference intervals. Eur J Endocrinol 2007;157:509-514.

32 World Health Organization: Iodine deficiency in Europe: A continuing health problem. Geneva, 2007.

-33 Negro R, Schwartz A, Gismondi R, Tinelli A, Mangieri T, Stagnaro-Green A: Increased pregnancy loss rate in thyroid antibody negative women with TSH levels between 2.5 and 5.0 in the first trimester of pregnancy. J Clin Endocrinol Metab 2010;95:E44-E48.

34 Alexander EK: Here's to you, baby! A step forward in support of universal screening of thyroid function during pregnancy. J Clin Endocrinol Metab 2010;95:1575-1577.

35 Dosiou C, Sanders GD, Araki SS, Crapo LM: Screening pregnant women for autoimmune thyroid disease: a cost-effectiveness analysis. Eur J Endocrinol 2008;158:841-851.

- 36 Haddow JE, McClain MR, Palomaki GE, Kloza EM, Williams J: Screening for thyroid disorders during pregnancy: results of a survey in Maine. Am J Obstet Gynecol 2006; 194:471-474.

37 Vaidya B, Hubalewska-Dydejczyk A, Laurberg P, Negro R, Vermiglio F, Poppe K: Treatment and screening of hypothyroidism in pregnancy: results of a European survey. Eur J Endocrinol 2012;166:49-54.

- 38 Klubo-Gwiezdzinska J, Burman KD, Van Nostrand D, Wartofsky L: Levothyroxine treatment in pregnancy: indications, efficacy, and therapeutic regimen. J Thyroid Res 2011;2011:843591.

-39 Glinoer D, Spencer CA: Serum TSH determinations in pregnancy: how, when and why? Nat Rev Endocrinol 2010;6:526-529.

40 La'ulu SL, Roberts WL: Ethnic differences in first-trimester thyroid reference intervals. Clin Chem 2011;57:913-915.

41 Bussen S, Steck T: Thyroid autoantibodies in euthyroid non-pregnant women with recurrent spontaneous abortions. Hum Reprod 1995; 10:2938-2940.

-42 Bagis T, Gokcel A, Saygili ES: Autoimmune thyroid disease in pregnancy and the postpartum period: relationship to spontaneous abortion. Thyroid 2001;11:1049-1053. 
43 Glinoer D, Soto MF, Bourdoux P, Lejeune B, Delange F, Lemone M, Kinthaert J, Robijn C, Grun JP, de Nayer P: Pregnancy in patients with mild thyroid abnormalities: maternal and neonatal repercussions. J Clin Endocrinol Metab 1991;73:421-427.

44 Lejeune B, Grun JP, de Nayer P, Servais G, Glinoer D: Antithyroid antibodies underlying thyroid abnormalities and miscarriage or pregnancy induced hypertension. $\mathrm{Br} \mathrm{J} \mathrm{Ob-}$ stet Gynaecol 1993;100:669-672.

45 Pratt D, Novotny M, Kaberlein G, Dudkiewicz A, Gleicher N: Antithyroid antibodies and the association with non-organ-specific antibodies in recurrent pregnancy loss. Am J Obstet Gynecol 1993;168:837-841.
46 Muller AF, Verhoeff A, Mantel MJ, Berghout A: Thyroid autoimmunity and abortion: a prospective study in women undergoing in vitro fertilization. Fertil Steril 1999;71:3034.

47 Rushworth FH, Backos M, Rai R, Chilcott IT, Baxter N, Regan L: Prospective pregnancy outcome in untreated recurrent miscarriers with thyroid autoantibodies. Hum Reprod 2000;15:1637-1639.

48 Poppe K, Glinoer D, Tournaye H, Devroey P, van Steirteghem A, Kaufman L, Velkeniers B: Assisted reproduction and thyroid autoimmunity: an unfortunate combination? J Clin Endocrinol Metab 2003;88: $4149-4152$
49 Poppe K, Glinoer D, Tournaye H, Schiettecatte J, Devroey P, van Steirteghem A, Haentjens P, Velkeniers B: Impact of ovarian hyperstimulation on thyroid function in women with and without thyroid autoimmunity. J Clin Endocrinol Metab 2004;89: 3808-3812.

$50 \mathrm{Kim} \mathrm{CH}$, Chae HD, Kang BM, Chang YS: Influence of antithyroid antibodies in euthyroid women on in vitro fertilization-embryo transfer outcome. Am J Reprod Immunol 1998;40:2-8.

51 Mecacci F, Parretti E, Cioni R, Lucchetti R, Magrini A, La Torre P, Mignosa M, Acanfora L, Mello G: Thyroid autoimmunity and its association with non-organ-specific antibodies and subclinical alterations of thyroid function in women with a history of pregnancy loss or preeclampsia. J Reprod Immunol 2000;46:39-50. 